\title{
Graduate nurse program coordinators' perceptions of role adaptation experienced by new nursing graduates: A descriptive qualitative approach
}

\author{
Karen Missen $^{1,2}$, Lisa McKenna ${ }^{2}$, Alison Beauchamp ${ }^{3}$ \\ 1. Federation University, Gippsland, Australia. 2. Monash University, Clayton, Australia. 3. Deakin University, Burwood, \\ Australia.
}

Correspondence: Karen Missen. Address: Federation University and Monash University, Australia.

Email: karen.missen@federation.edu.au

Received: August 14, 2014

DOI : $10.5430 /$ jnep.v4n12p134

Accepted: September 28, 2014

URL: http://dx.doi.org/10.5430/jnep.v4n12p134

\section{Abstract}

Aims: This research explores the challenges that new nursing graduates experience whilst adapting to their new role in their first year of practice. These challenges are presented from the perspectives of Graduate Nurse Program Coordinators in the state of Victoria, Australia, previously not described in the literature.

Background: Each year, thousands of new nursing graduates join the workforce in Australia, with many suffering major stressors and dissatisfaction in their first year of practice. Much has been written about challenges faced by this group from their own perspectives, yet nothing has been heard from the perspectives of those who support them; that is, the coordinators of year-long graduate nurse transition programs.

Methods: This descriptive qualitative study used individual, semi-structured interviews to access information and perceptions from sixteen Graduate Nurse Program Coordinators about the challenges experienced by nursing graduates in their first year of practice. Transcripts were thematically analysed to reveal reoccurring themes and sub-themes.

Results: The interviews provided an insight into various challenges that nursing graduates experience in relation to role adaptation in their first year of practice. Nursing graduates found difficulties with reality shock, work-life balancing and having unrealistic assumptions in their capacity to work, assuming they should be at a higher level despite being a beginner practitioner.

Conclusions: This study reinforces the need for education providers to maintain currency in their undergraduate nursing programs and to work closely with health care services in providing a quality clinical experience to all nursing students. It also provides evidence that graduate transition programs are essential, with Graduate Nurse Program Coordinators performing a crucial role in providing appropriately planned strategies to support graduates through this vulnerable time.

\section{Key words}

New graduate nurse, Reality shock, Transition programs, Qualitative, Adaptation

\section{Introduction}

The transition from nursing student to practising nurse is complex and the beginning practitioner frequently experiences challenges in adapting to their new professional role. In Victoria, Australia, nursing students undertake a three-year 
full-time Bachelor of Nursing program and on successful completion of this register with the national nursing authority as qualified Registered Nurses. The majority of nursing graduates then seek employment in a supported position in a graduate nurse program within the healthcare setting to assist with assimilating newly learnt knowledge into practice. These health care based programs have been designed to give graduates exposure to a variety of clinical settings and provide support and educational opportunities to assist with their adjustment from student to registered nurse in the fast paced, ever changing clinical environment ${ }^{[1-3]}$. In Victoria, these programs are not mandatory but are highly recommended, to the point that most health care managers will not employ newly qualified nurses outside these programs. Graduate Nurse Program Coordinators (GNPC) are employed at health care facilities to coordinate these work-based programs and are responsible for the professional development of graduates to ensure safe clinical practice and positive patient outcomes ${ }^{[1]}$. This research explores the challenges new nursing graduates experience from the perspectives of GNPCs. This important group is largely unheard in the existing literature, despite being central to the transition process.

Graduates frequently perceive their first year in health care settings as a period of considerable stress stemming from fears such as; inadvertently harming a patient, medication errors, litigation, feeling under-prepared and wondering how they would cope in unpredictable crisis situations such as during a medical emergency ${ }^{[4-7]}$. Research suggests that nursing graduates are not fully prepared for the shift work, workplace culture, high acuity of patients, fast-paced technological environment and clinical challenges they are presented with in their first year of clinical practice ${ }^{[8,9]}$. Some researchers argue this is because undergraduate students have limited clinical placement experience and are rarely given responsibility for a full patient workload throughout the entirety of their program. This supernumerary status effectively shields them from the reality and accountabilities of the clinical environment ${ }^{[10]}$.

Historically it has been noted that many nursing graduates experience shock-like reactions whilst adapting to their new roles during their first year of employment ${ }^{[4,6,11-13]}$. Kramer ${ }^{[14]}$ devised the expression 'reality shock' over four decades ago, describing it as a wide disparity between graduates' expectations and their actual experiences in the clinical environment. This phenomenon creates feelings of doubt and dissatisfaction, with graduates reaching a crisis point and choosing to leave their careers if these feelings are not resolved ${ }^{[9]}$. Researchers have also reported discrepancies between the skills and theory nurses learn during their undergraduate education and their actual practices in their first year of employment in health care settings ${ }^{[7,10,13,15]}$. This theory-practice gap has been shown to affect the graduate's work readiness in their first year of employment and tends to lead to high attrition rates through job dissatisfaction and career disillusionment ${ }^{[4-6,16,17]}$.

Internationally, health care facilities offer a range of orientation programs that aim to assist and support new nurses in their transition to professional roles through integrating theory and practice ${ }^{[10,18,19]}$. In Victoria, structured graduate nurse programs are funded by the Victorian Department of Health ${ }^{[1]}$ and GNPCs are employed to supervise these year-long transition programs. Programs offer opportunities for beginning practitioners to develop confidence and competence within supportive environments. Despite these programs being in existence since the mid-1990s research exploring nursing graduates' perceptions still describe this first year as problematic filled with many challenges and difficulties ${ }^{[10,20,21]}$. It is therefore important to identify what can be done to ensure nursing graduates are work ready and further supported during this adaptation period to avoid high attrition rates and job dissatisfaction. Despite an abundance of research exploring graduates' perspectives, a review of the literature revealed no studies reporting GNPCs' perceptions of the challenges new nursing graduates experience in their first year of employment. Opinions from this group are significant, as GNPCs are responsible for recruiting new nursing graduates and providing both educational and emotional support through this vulnerable transitional period. This qualitative study adds previously unheard voices by exploring GNPC's viewpoints on this subject, with the aim of describing major challenges that nursing graduates experience and gaining an understanding of strategies GNPCs employ to assist new nurses whilst employed in year-long graduate nurse programs. 


\section{Methods}

Employing a descriptive qualitative approach, we used individual semi-structured interviews to explore GNPCs' perceptions of challenges experienced by nursing graduates in their first year of practice. This method was chosen due to the lack of evidence in the literature from this group of participants to provide in-depth knowledge on their experiences working with new nursing graduates. GNPCs were recruited from general graduate nurse programs listed in the publicly accessible Postgraduate Medical Council of Victoria (PMCV) Hospital/Health Service directory. The PMCV administers an online computer matching service in Victoria for final year nursing students and hospitals to submit their ranked preferences for their graduate year. Fifty-four GNPCs were emailed invitations to participate, with explanatory letters outlining the aims of the study and requirements of participation and consent forms.

\subsection{Participants}

Sixteen GNPCs from Victoria, voluntary participated in this study. Participants came from various health care venues including: metropolitan, regional, community, and also private and public facilities. The majority were female (thirteen) with three males participating. Overall experience as a GNPC ranged from 1.5-26 years. All health facilities involved provided one-year transition programs for new graduates, with the numbers of graduate nurses in each program ranging from 4 to 110.

\subsection{Ethical considerations}

Formal ethical clearance was provided by Monash University Human Research Ethics Committee. Written consent was obtained from all participants and confidentiality was assured as no participant or organisation would be named in reporting.

\subsection{Data collection}

All sixteen interviews were undertaken by one experienced researcher, in June and July 2013. Each participant was interviewed once, with interviews lasting between 40 and 75 minutes, two taking place face-to-face at the participant's place of employment and the remaining fourteen conducted by telephone due to lengthy travelling distances. The two main research questions from the eight questions in the interview schedule prompting the interviewees on this topic were:

- What do you think are the greatest challenges that nursing graduates face in their first year of employment?

- In your view, how well are nursing graduates adequately prepared for graduate practice on completion of their undergraduate studies?

All interviews were audio-recorded and transcribed verbatim by the researcher who undertook the interviews and was familiar with the content. Each participant was emailed their transcript to determine accuracy and to establish credibility of the data prior to analysis. Two participants requested minor amendments be made to their transcripts. Interviews were assigned numbers to protect participants' identities in reporting findings.

\subsection{Data analysis}

A manual systematic objective exploration of transcripts was undertaken to identify explicit and implicit themes using thematic analysis informed by the six step framework suggested by Guest et al. ${ }^{[22]}$. These steps involved the three researchers independently reading and rereading each transcript, one by one, coding key elements of data and proposing preliminary themes and subthemes. These themes and sub-themes were refined and then validated as a group to enhance trustworthiness ${ }^{[22]}$. This method was deemed appropriate for this study to deduce participants' experiences as GNPCs and identify themes that described the main challenges they perceived nursing graduates' experienced in their first year of clinical practice. This paper reports on one of the three final identified themes, 'role adaptation', and its associated sub-themes. 


\section{Results}

GNPCs' comments gave insight into the various challenges that graduates experience in relation to role adaptation and extend on what graduates themselves have described previously. Within this theme of role adaptation, three-subthemes emerged: getting into the real world, work-life balancing and unrealistic assumptions.

\subsection{Getting into the real world}

All GNPCs acknowledged that graduates struggled with disconnect between their ideals of nursing and actual experiences in the clinical setting, which created an inner conflict and confusion about the actual role of the nurse. It was perceived by GNPCs that nursing students were often not fully exposed to the real world demands of nursing in their undergraduate preparation, leading to reality shock and dissatisfaction when they became independent practitioners.

It is usually early on they [graduates] then come to the realisation of what it means, what the actual role of the registered nurse is and the expectations of them. Which sometimes I think when they have been in the undergraduate role they may not have been aware of. (GNPC1)

Another participant noted:

I probably would say that sort of reality shock, really stemming back from the 70s... So how they [graduates] see it at uni [university] isn't quite how it is in the real world. That your patients are not little robots in bed and now I can do this, and now I can start to do that. People do fall out of bed, people are incontinent, you have confused patients that might lash out at you, patients that die, so those sorts of issues. (GNPC5)

Four GNPCs discussed the mental strain and sensory overload that graduates experienced in their first few months of employment. Nursing workloads are not only physically demanding but also intellectually intense. Graduates have to comprehend and prioritise a vast amount of information on a daily basis from various health professionals on differing patient conditions and interventions. This may lead to mental strain contributing to emotional tiredness and inability to cope initially in their new role.

I think it is adjusting to the role and that includes; adjusting to shift work and ... getting their nursing identity. So thinking like a nurse, you know you walk into somewhere and your brain is in one particular gear and you get all of this information thrown at you every day from different people about different patients' conditions and the reality is they are not synthesising all that information together. So what they are really trying to do, they are trying to figure out what are the really important things that they need to know and that is a huge struggle for them at first. (GNPC15)

All participants noted that graduates hit a crisis point at some stage during their transition year leading to discontent and doubt about their career choice. This role conflict was found to push graduates into questioning whether or not to remain in the profession. Timeframes for this crisis point were seen to vary anywhere between the first two to six months of employment. Ten participants discussed strategies that they had put in place to assist nursing graduates through this time. Seven GNPCs reported having put in mandatory annual leave at highlighted periods throughout the year ensuring nursing graduates were reenergised for their next rotation and continued learning.

...maybe about the 3 month period, they [graduates] sort of start to reassess, and what I have put in place is to ensure that the grads have a holiday at about July/August, and have made it a point at orientation that 2 weeks is booked as soon as they walk in the door, so that they [graduates] know that after that intense few months of learning that they can have a bit of a break and then come back fresh for the second half of the year. (GNPC6)

Another participant commented:

We have an intake at the beginning of February and we find in April/May their sick leave goes sky high. So we did change that they needed to have a week of annual leave, during that period of time, mandatory. (GNCP7) 
Another strategy reported by three GNPCs was to provide educational sessions on stress management, work-life balance and looking after oneself. These sessions were held during study days at recognised crisis points throughout the year.

Within six months they all hit the brick wall ... so some study days we run are about looking after yourself. We bring the nurses from the wellbeing program up to talk to the grads about alcohol and other drugs and they talk to them about mental health, they talk to them about empathy fatigue, and signs that they are starting to stress ...not important day one because you are too busy working out where the old pan room is but is really important half way through the year when they [graduates] are all starting to fall apart. (GNPC2)

\subsection{Work life balancing}

Participants were asked what they perceived to be the greatest challenges that graduates experience in their first year of practice. All reported that one major challenge for new graduates was juggling shift work with normal life. They reported that beginning nurses found it difficult to adapt to shift work, working weekends, public holidays and several shifts in a row, especially the late-early changeover, contributing to physical and emotional fatigue.

“...the majority, above $75 \%$, of graduates get tired with shift work and have difficulties adjusting to their new schedule, though it does vary from grad to grad.” (GNPC4)

Often younger nurses who had never worked full-time or nurses with young families tended to struggle more than others and elected to decrease their hours to assist in coping with their new professional role. One participant acknowledged:

... so things like work life balance. You know the majority of our graduates are young...we obviously have a cohort that have had life or work experiences in the past but the majority of them are in their early twenties and they can often struggle with the demands of shift work, night duty, the afternoon-evening swap over to the morning shift etc. Some of them opt to reduce their hours to assist them with dealing with that. (GNPC1)

Another participant agreed that some graduates wanted to decrease their hours and noted some who reach a crisis point in their new career reported that they were more satisfied at their previous employment, where they had less responsibility, better hours and often similar pay.

... half way through the year when they [graduates] are all starting to fall apart, and they [graduates] are all looking to decrease their EFT and they are not sure if they can do this, start to query was I better off at Coles [supermarket].(GNPC2)

Nursing graduates' new work schedules were also seen to affect their personal lives, taking time for them to adapt to not spending weekends and public holidays with their friends and family.

...the biggest challenge is that work life balance... they are getting into the shift work and realising they can't go out with their friends on Friday or Saturday nights or have all of the weekends off or have all of the public holidays, or the special days off. (GNPC8)

\subsection{Unrealistic assumptions}

There was a strong view among ten participants that graduates often had idealistic beliefs whereby they compared themselves to more experienced nurses and assumed they should be working at higher levels despite only being in their first year of practice. This created further inner turmoil and uncertainty for graduates.

Nobody expects you to be performing as a practitioner of 10 years, they expect you to be exactly where you are, so just allow yourself to learn and to grow, don't expect yourself to be up here and performing...I think they have that unrealistic expectation of themselves as well where they should be performing. We want you to be safe, we want you to use common sense, we want you to have that critical thinking but we know that you are at this level. (GNCP9) 
Another unrealistic assumption noted by participants was that graduates had a fear of appearing incompetent and being embarrassed in front of their colleagues. They often felt they could not ask their preceptors, educators or managers for clinical advice for fear of appearing stupid, and this resulted in them trying to manage on their own.

We have got grads who when we [clinical teachers] walk down the corridor duck behind the curtain because they don't want to be seen as incapable or incompetent. We actually have to pull them out from behind the curtains and say you are missing the point, this 12 months is when you want to be trying to get me every time you can, to say; tell me about this, am I doing this right, or can I do this better or this is the way that I have structured my day have I missed anything? (GNPC2).

A point made by three participants was that some graduates did not recognise their position in the hierarchy of the clinical setting and assumed they were entitled to have their demands adhered to. They did not understand their role as junior nurse and the negotiation required to make it fair for everyone, which could be frustrating for permanent nursing staff, as reflected in the following quote:

We have got grads ... who are already telling us, a couple of them ... that they need Christmas off and these sorts of things. The truth is, is that is plain not going to work that they are coming into a workforce ... as the juniors, and you want Christmas off, well then it is a negotiation thing...it certainly is not a done deal. (GNCP2)

Another participant commented that graduates often thought that other clinical areas were more exciting than the one they were employed in. They did not realise how important it was to integrate theory and practice and become competent registered nurses first and then experience specialised areas.

...they want to swap and go to a different area because it is not exciting enough for them or whatever it might be and it is like 'no' think about this, ...you have got plenty of time to go down all of these different avenues in your career, just focus on consolidating your skills now and learning as much as you can in the environment that you are in because they all bridge to other areas in your future. (GNPC9)

\section{Discussion}

This study sought to extend what is already known and better understand the challenges faced by new graduates, by examining the perspectives of an important, but previously unheard group central to graduates' transition. In our interviews, GNPCs discussed challenges they perceived nursing graduates experienced in their adaptation from nursing student to practising nurse as well as strategies they employed to meet these challenges. Findings from our study indicate that GNPCs viewed work-life balance as a constant challenge in a new graduates' working life. This is consistent with other studies in which new graduates found adjusting to shift work difficult and both mentally and physically demanding and socially isolating ${ }^{[23,24]}$. Compounding this issue, research by Halfer and Graf ${ }^{[25]}$ suggest that nursing graduates also go through a grieving process with the loss of their academic schedule and support network of peers and academics. To assist graduates in coping with their new work-schedule they need exposure as students to the various shifts, including weekends, during their clinical placements particularly in their third year of study ${ }^{[26]}$.

Universities and health care settings need to place more emphasis on clinical placements; ensuring nursing students encounter the real world of nursing by enabling them to experience various shifts and working weekends. An initiative in some acute care hospitals in Australia is a joint partnership between hospitals and universities with hospital-based clinical schools of nursing. Students enrolled at these universities receive theoretical and practical content jointly taught within the clinical setting by clinically based educators and academics, with the key aim of improving graduates' preparedness for practice ${ }^{[15]}$. Watt and Pascoe ${ }^{[15]}$ found graduates who undertook their final year of undergraduate studies at a clinical school in a large metropolitan hospital were more familiar with the environment as the real world was brought directly into the classroom. Findings from our study support such changes to undergraduate nursing education. 
Another noteworthy finding in this study was that during the role adjustment period, nursing graduates hit a crisis point between two to six months into the program. This crisis usually occurs when a graduate encounters systems of values in the clinical setting that are in direct contrast with the roles and values previously learnt in their undergraduate education ${ }^{[6]}$. Some participants in this study discussed strategies they used to support nursing graduates through these difficult times such as mandatory annual leave, and health and well-being sessions at predetermined times throughout the year. These strategies should be acknowledged and included in all transition programs to assist graduates during their first year of practice. Kring et al. ${ }^{[27]}$ found in the United States that the satisfaction level of nursing graduates showed a decline from three to twelve months meaning that the transition time may be longer than nurses experienced a decade ago, thereby lengthening the reality shock phase. The authors believed that this was due to the intensely complex work environments of modern acute care hospitals and suggest that transitional programs may need to be revised to accommodate longer transition periods ${ }^{[27]}$. This requires particular consideration and further study.

Findings from this study suggest that nursing graduates have unrealistic assumptions of the level they should be practising at, comparing themselves to experienced nurses. This finding has not been described specifically elsewhere in previous research, though similar research has found that graduates tended to have high self-expectations and felt that it was a personal failing if they did not get everything done in their shift or failed to provide the desired standards of care or had to ask for assistance ${ }^{[5,6,28]}$. Duchscher ${ }^{[6]}$ found that graduate nurses went to great lengths to hide feelings of inadequacy from their nursing colleagues so as not to appear incompetent. This was exacerbated by the fact that graduates did not want to question or ask for advice from their preceptor/mentors whose workloads were often heavier than their own ${ }^{[6]}$. An important strategy noted was to provide experienced consistent preceptors who are approachable, understanding and have good teaching skills to support graduates, help them understand their limitations and build knowledge in their first year of practice ${ }^{[28,29]}$. Olson ${ }^{[29]}$ summed this up in her study in which nursing graduates referred to their preceptors as a 'life preserver' illustrating how important it is to have a good preceptor during this time.

\section{Limitations}

We conducted this research in only one state of Australia, Victoria; therefore findings may not be transferable to other states or countries. Comparable studies undertaken both nationally and internationally would provide further conclusive evidence on the challenges and stressors that nursing graduates experience in their first year of practice.

\section{Conclusion}

This study, which explored the perceptions of GNPCs on the challenges experienced by newly qualified nurses in their graduate programs, has reiterated that graduates struggle with the transition from student to registered nurse. Our findings provide key insights into the difficulties graduates face when adapting to their new role, in particular related to shift work, reality shock and having unrealistic assumptions, from a perspective previously unheard in the literature. This new knowledge will assist in developing additional strategies to further support new graduates. This study reinforces the need for education providers to maintain currency in their undergraduate nursing programs and to work closely with health care services in providing a quality clinical experience to all nursing students, exposing them safely to the 'real world' of nursing. It also provides evidence that graduate transition programs are essential, with GNPCs having a crucial role in providing appropriately planned strategies to support graduates through this vulnerable time.

\section{Acknowledgement}

We acknowledge and thank the graduate nurse program coordinators who participated in this study.

\section{References}

[1] Healy M, Howe V. Study of Victorian Early Graduate Programs for Nurses and Midwives. Nursing and midwifery policy wellbeing, integrated care and ageing department of health: Final research report. Nursing and Midwifery Policy, Wellbeing, integrated Care and Ageing, Department of Health, TNS,Hawthorn, Victoria.2012. 
[2] Rush,KL, Adamack M, Gordon J, Lilly M. Janke R. Best practices of formal new graduate nurse transition programs: An integrative review. International Journal of Nursing Studies. 2012; 50(3): 345-356. PMid:22795800 http://dx.doi.org/10.1016/j.ijnurstu.2012.06.009

[3] Missen K, McKenna L, Beauchamp A. Satisfaction of newly graduate nurses enrolled in transition-to-practice programmes in their first year of employment: a systematic review. Journal of Advanced Nursing. 2014. PMid:24989716 http://dx.doi.org/10.1111/jan.12464

[4] Goh K. Watt E. From 'dependent on' to 'depended on': the experience of transition from student to registered nurse in a private hospital graduate program. Australian Journal of Advanced Nursing. 2003; 21(1): 14-20.

[5] Mooney M. Facing registration: the expectations and the unexpected. Nurse Education Today. 2007; 27(8): $840-847$. PMid:17234304 http://dx.doi.org/10.1016/j.nedt.2006.11.003

[6] Duchscher JEB. Transition shock: the initial stage of role adaptation for newly graduated Registered Nurses. Journal of Advanced Nursing. 2009; 65(5): 1103-1113. PMid:19183235 http://dx.doi.org/10.1111/j.1365-2648.2008.04898.x

[7] Duclos-Miller PA. Successful Graduate Nurse Transition: Meeting the Challenge. Nurse Leader. 2011; 9(4): 32-49. http://dx.doi.org/10.1016/j.mnl.2011.05.006

[8] Bail K,. Cook R, Gardner A, Grealish L. Writing ourselves into a web of obedience: A nursing policy analysis. International Journal of Nursing Studies. 2009; 46(11): 1457-1466. PMid:19481204 http://dx.doi.org/10.1016/j.ijnurstu.2009.04.005

[9] Health Workforce Australia[HWA]. Health Workforce 2025- Doctors, Nurses and Midwives. 2012; 2.

[10] Evans J. Boxer E. Sanber S. The strengths and weaknesses of transitional support programs for newly registered nurses. Australian Journal of Advanced Nursing. 2008; 25(4): 16-22.

[11] Dyess, S.M., \& Sherman, R.O. The First Year of Practice: New Graduate Nurses' Transition and Learning Needs. The Journal of Continuing Education in Nursing. 2009; 40(9): 403-410. PMid:19754027 http://dx.doi.org/10.3928/00220124-20090824-03

[12] Cubit KA. Tailoring a Graduate Nurse Program to meet the needs of our next generation nurses. Nurse Education Today. 2010; 31(1): 65-71. PMid:20417996 http://dx.doi.org/10.1016/j.nedt.2010.03.017

[13] Stacey G, Hardy P. Challenging the shock of reality through digital storytelling. Nurse Education in Practice. 2011; 11(2): 159-164. PMid:20829115 http://dx.doi.org/10.1016/j.nepr.2010.08.003

[14] Kramer M. Reality shock: Why nurses leave nursing. C.V. Mosby Co. St Louis.1974.

[15] Watt E, Pascoe E. An exploration of graduate nurses' perceptions of their preparedness for practice after undertaking the final year of their bachelor of nursing degree in a university-based clinical school of nursing. International Journal of Nursing Practice. 2013; 19: 23-30. PMid:23432885 http://dx.doi.org/10.1111/ijn.12032

[16] Newton JM, McKenna L. The transitional journey through the graduate year: A focus group study. International Journal of Nursing Studies. 2007; 44(7): 1231-1237. PMid:16867302 http://dx.doi.org/10.1016/j.ijnurstu.2006.05.017

[17] Cheeks P. A new-graduate program: empowering the novice nurse. Journal for Nurses in Staff Development. 2010; 26(5): $223-227$. PMid:20885146 http://dx.doi.org/10.1097/NND.0b013e3181993b72

[18] Levett-Jones T. FitzGerald M. A review of graduate nurse transition programs in Australia. Australian Journal of Advanced Nursing. 2005; 23(2): 40-45. PMid:16502968

[19] Cubit KA, Leeson BG. Is there a case for tailoring graduate programs for nurses who have previously practiced as Enrolled Nurses? Nurse Education Today. 2009; 29: 891-894. PMid:19640617 http://dx.doi.org/10.1016/j.nedt.2009.06.013

[20] Clark T, Holmes S. Fit for practice? An exploration of the development of newly qualified nurses using focus groups. International Journal of Nursing Studies. 2007; 44(7): 1210-1220. PMid:16872614 http://dx.doi.org/10.1016/j.ijnurstu.2006.05.010

[21] Laschinger HKS, Grau AL. The influence of personal dispositional factors and organizational resources on workplace violence, burnout, and health outcomes in new graduate nurses: A cross-sectional study. International Journal of Nursing Studies. 2012; 49(3): 282-291. PMid:21978860 http://dx.doi.org/10.1016/j.ijnurstu.2011.09.004

[22] Guest G, MacQueen KM, Namey EE. Applied Thematic Analysis. Sage Publications, London. 2012.

[23] Clare J, van Loon A. Best practice principles for the transition from student to registered nurse. Collegian. 2003; 10(4): 25-31. http://dx.doi.org/10.1016/S1322-7696(08)60073-6

[24] McKenna L, French J. Rethinking student night duty placements. Australian Journal of Advanced Nursing. 2009; 27(2): 27-34.

[25] Halfer D., Graf E. Graduate nurse perceptions of the work experience. Nursing Economic\$. 2006; 24(3): 150-155. PMid:16786830

[26] West SH, Ahern M, Byrnes M, Kwanten L. New Graduate Nurses Adaptation to Shift Work: Can we help? 2007; Collegian, 14(1): 23-30. http://dx.doi.org/10.1016/S1322-7696(08)60544-2

[27] Kring D, Mueller B, Letvak S. Graduating nurses face a new reality. Men in Nursing. 2008; 3(2): 22-26. http://dx.doi.org/10.1097/01.MIN.0000316372.49066.2d

[28] Litchfield C, Chater K. Can I do everything? Time management in neonatal unit. Australian Journal of Advanced Nursing. 2007; 25(2): 36-45.

[29] Olson ME. The "Millenials": first year in practice. Nursing Outlook. 2009; 57(1): 10-17. PMid:19150262 http://dx.doi.org/10.1016/j.outlook.2008.06.001 